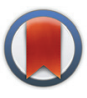

CrossMark \& click for updates

Cite this: Polym. Chem., 2016, 7, 2759

Received 24th February 2016 , Accepted 21st March 2016

DOI: $10.1039 / c 6 p y 00339 g$

www.rsc.org/polymers

\title{
Ultralight open cell polymer sponges with advanced properties by PPX CVD coating $†$
}

\author{
Gaigai Duan, Shaohua Jiang, Tobias Moss, Seema Agarwal and Andreas Greiner*
}

Ultralight polyacrylate sponges were prepared from dispersions of short electrospun polymer fibres by freeze drying and coated with poly(p-xylylene) (PPX) by chemical vapour deposition (CVD). The PPX coating of the sponges increased the compression strength, the water contact angle, and the solvent resistance significantly without significant alteration of the sponge morphology.

\section{Introduction}

Ultraporous, ultralight, three-dimensional (3D) materials are very attractive due to their high porosity and elasticity that makes them suitable for various fields, including energy applications, absorber materials, insulating materials, and tissue engineering. ${ }^{1-4}$ Among these materials, 3D ultralight polymer scaffolds assembled from electrospun fibres recently experienced a fast development in applications for tissue engineering, ${ }^{5-7}$ microbial fuel cells, ${ }^{8}$ oil adsorption, ${ }^{9}$ and oil/ water separation. ${ }^{10}$ Recently, our group developed novel ultralight 3D sponges from the dispersion of short electrospun fibres, which possessed ultralow density $\left(2.7-9.1 \mathrm{mg} \mathrm{cm}^{-3}\right)$ and high porosity (99.6\%). ${ }^{11}$ These sponges are highly breathable open cell solids. The sponges showed applications in cell culture and high uptake of hydrophobic liquids. ${ }^{11}$ In another recent report, $\mathrm{Xu}$ et al. adopted a similar strategy and prepared a 3D nanofibrous polycaprolactone (PCL) scaffold for bone tissue engineering. ${ }^{12}$ However, due to the highly porous structures, these 3D fibrous sponges/scaffolds showed poor mechanical properties, which would greatly limit their practical applications. A solution for the disadvantage of such sponges could be additional coatings on the surface of the fibres, in particular at the junction points. Poly(p-xylylene) (PPX) prepared by chemical vapour deposition (CVD) could be an ideal coating material due to its homogeneous and conformal surfaces, good adhesion to other materials, chemical resistance, excellent biocompatibility, and thermal stability. ${ }^{13-15}$ It can be used for hydrophobic coating for moisture barriers, ${ }^{16,17}$ reinforcement of microstructures ${ }^{18}$ and protection materials for plastic, rubber, and metals from a harsh environment. ${ }^{19,20}$

Macromolecular Chemistry II and Bayreuth Center for Colloid and Interfaces, Universität Bayreuth, Universitätsstraße 30, 95440 Bayreuth, Germany.

E-mail: greiner@uni-bayreuth.de; Fax: +49-921-553393

$\dagger$ Electronic supplementary information (ESI) available. See DOI: 10.1039/ c6py00339g
In this work, PPX was coated onto the ultralight polymer fibre sponges. By varying the coating thickness, PPX reinforced composite sponges exhibited tuneable properties including densities, mechanical properties, water contact angle, and solvent resistance.

\section{Experimental}

\section{Materials}

Methyl acrylate (MA, Aldrich, 99\%) and methyl methacrylate (MMA, Aldrich, 99\%) were purified by passing through a neutral aluminium oxide column. 2,2'-Azobis (isobutyronitrile) (AIBN, Fluka, 98\%) was recrystallised from methanol (Aldrich, 99.8\%). Parylene N (Specialty Coating Systems), polyacrylonitrile $\left(M_{\mathrm{w}}=150000\right.$, polyscience Inc.), dimethyl sulfoxide (DMSO, Fisher Chemical, 99.99\%), dimethyl formamide (DMF, Fisher Chemical, 99.99\%), dioxane (technical grade), and acetone (technical grade) were used as received. 4-Methacryloyloxybenzophenone (MABP) was synthesised according to a previous report. $^{21}$

\section{Preparation of sponges}

The polymer fibre sponges were prepared according to our previous report. ${ }^{11}$ In brief, copolymer poly(MA-co-MMA-MABP) was prepared by radical copolymerisation of MMA (13.5 ml), MA (17.3 ml), and MABP (4.681 g) using AIBN (0.293 g) as initiator in DMSO at $70^{\circ} \mathrm{C}$ for 5 hours. The copolymer was precipitated in methanol and dried in a vacuum oven at $40^{\circ} \mathrm{C}$ for 2 days. The obtained poly(MA-co-MMA-MABP) had a molar mass $\left(M_{\mathrm{n}}\right)$ of $2.43 \times 10^{5}$ as determined by gel permeation chromatography using THF as the eluting solvent against poly (methyl methacrylate) standards.

$6.17 \mathrm{~g}$ of poly(MA-co-MMA-MABP) were dissolved in DMSO with a concentration of $20 \mathrm{wt} \%$. A $13.2 \mathrm{wt} \%$ PAN solution was prepared by dissolving PAN in DMF. 
Table 1 Detailed information about short electrospun fibre dispersions and densities of the sponges

\begin{tabular}{llll}
\hline Sponge & $\begin{array}{l}\text { Volume of short } \\
\text { fibre dispersion }(\mathrm{ml})\end{array}$ & $\begin{array}{l}\text { Volume of } \\
\text { dioxane }(\mathrm{ml})\end{array}$ & $\begin{array}{l}\text { Density } \\
\left(\mathrm{mg} \mathrm{cm}^{-3}\right)\end{array}$ \\
\hline 1 & 65 & 0 & 8.42 \\
2 & 60 & 5 & 7.43 \\
3 & 50 & 15 & 6.61 \\
4 & 40 & 25 & 5.16 \\
5 & 30 & 35 & 4.34
\end{tabular}

The solution (17.8 wt\%) for electrospinning was prepared by mixing $26.2 \mathrm{~g}$ of poly(MA-co-MMA-MABP) solution in DMSO (20 wt\%), $2 \mathrm{~g}$ of PAN solution in DMF (13.2 wt\%) and $2.68 \mathrm{~g}$ of acetone. Electrospinning was performed by applying a voltage of $9 \mathrm{kV}$ and a flow rate of $1.5 \mathrm{ml} \mathrm{h}^{-1}$ in $55 \%$ humidity. The electrospun fibres were collected on aluminium foil and dried in a vacuum oven at $40^{\circ} \mathrm{C}$ for $24 \mathrm{~h}$.

$1.17 \mathrm{~g}$ of the above electrospun fibres were cross-linked using UV light (UV lamp 250GS) with a distance of $15 \mathrm{~cm}$ for $5 \mathrm{~h}$. Then the cross-linked nanofibres were cut into short fibres with a length of $150 \pm 30 \mu \mathrm{m}$ in $350 \mathrm{ml}$ of dioxane with a razor blade at a rotation of $5000 \mathrm{rpm}$ for $45 \mathrm{~s}$. Different short fibre dispersions were prepared by controlling the volume of the above short fibre dispersion and dioxane (Table 1). Sponges with different densities of 8.42, 7.43, 6.61, 5.16, and $4.34 \mathrm{mg} \mathrm{cm}^{-3}$ were prepared by freeze-drying the above short fibre dispersions in cylindrical glass tubes at $0.03 \mathrm{mbar}$ for $48 \mathrm{~h}$.

\section{PPX coating on sponge fibres}

The above sponges were put in the deposition chamber of a CVD coater. For CVD coating, $170 \mathrm{mg}$ of [2.2]paracyclophane were sublimed at $150{ }^{\circ} \mathrm{C}$ followed by pyrolysis at $650{ }^{\circ} \mathrm{C}$ in a pyrolysis oven of the coater under reduced pressure. The pyrolysed monomer gas was deposited on the fibres of the sponges at $20{ }^{\circ} \mathrm{C}$ under 52 mtorr in the deposition chamber and formed a PPX film with $100 \mathrm{~nm}$ thickness. Different samples with varied coating thickness of PPX (100, 280, 360, and $1000 \mathrm{~nm}$ ) were made by changing the amount of the precursor.

\section{Characterisation}

The morphology of sponges was characterised by scanning electron microscopy (SEM, Zeiss Leo 1530) and all the samples were sputtered with $3 \mathrm{~nm}$ thick platinum before measurements. A compression test was done using a Z 2.5 machine with a $20 \mathrm{~N}$ sensor at a speed of $10 \mathrm{~mm} \mathrm{~min}^{-1}$. The samples for the compression test were cut into cylindrical shape with a diameter of $20 \mathrm{~mm}$ and a height of $8 \mathrm{~mm}$. Each of these samples was compressed once, released, and compressed again for measurement. The water contact angle was measured by using a G10 contact angle analysis system (Krüss, Hamburg, Germany) using an $8 \mu$ l water droplet. The PPX coating thickness was measured using a Veeco Dektak 150 profilometer. An indirect method was used for thickness determi- nation. A glass side was coated simultaneously to the sponge. The PPX coated layer on the glass slide was cut at three different positions and the thickness of the layer was determined by analysing the step height with the profilometer. The average height at the three positions was used as the coating thickness.

\section{Results and discussion}

Electrospun nanofibres were fabricated from a blended solution of poly(MA-co-MMA-MABP) and PAN. The fibres have a smooth surface without any beads and the diameter of the fibre was $1000 \pm 100 \mathrm{~nm}$ (Fig. 1). The polymer sponge prepared from short electrospun nanofibre dispersion was free-standing with a $3 \mathrm{D}$ cylindrical-shape with a diameter of $20 \pm 2 \mathrm{~mm}$ (Fig. 1, inset).

The pore size could be tuned by controlling the density of the sponge. As shown in Fig. 2, the pore size of the sponge became larger as the density decreased from 8.42 to $5.16 \mathrm{mg} \mathrm{cm}^{-3}$.

The average fibre diameter of the sponge was about $1000 \pm$ $100 \mathrm{~nm}$ (Fig. 2D), which is similar to the starting nanofibres before cutting and freeze-drying. The fibre diameter increased after PPX coating depending upon the coating thickness (Fig. 2E). The increasing PPX thickness led to the film formation around the entanglement position of the fibres (Fig. 2E), which could contribute to the increase in compression strength observed for the coated sponges (see below). Fig. 2F shows the cross-sectional morphology of the PPX coated fibres, where a core (original sponge fibre)-shell (PPX) morphology was clearly obvious. CVD (gas phase polymerisation) of PPX has the advantage that it provides uniform coating without film deposition on the surface. PPX coating also provides an additional way of tuning the density of sponges. The sponge density increased with an increase in PPX thickness (Table 2). For uncoated sponges, the density is controlled by the amount of short fibres in the dispersion for

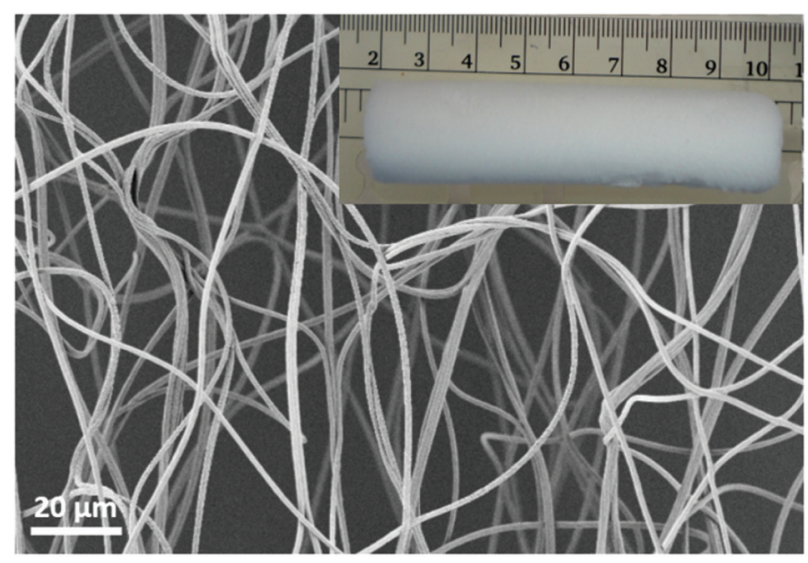

Fig. 1 SEM image of an electrospun nanofibre mat and the digital photo of sponge made after cutting and drying (inset). 

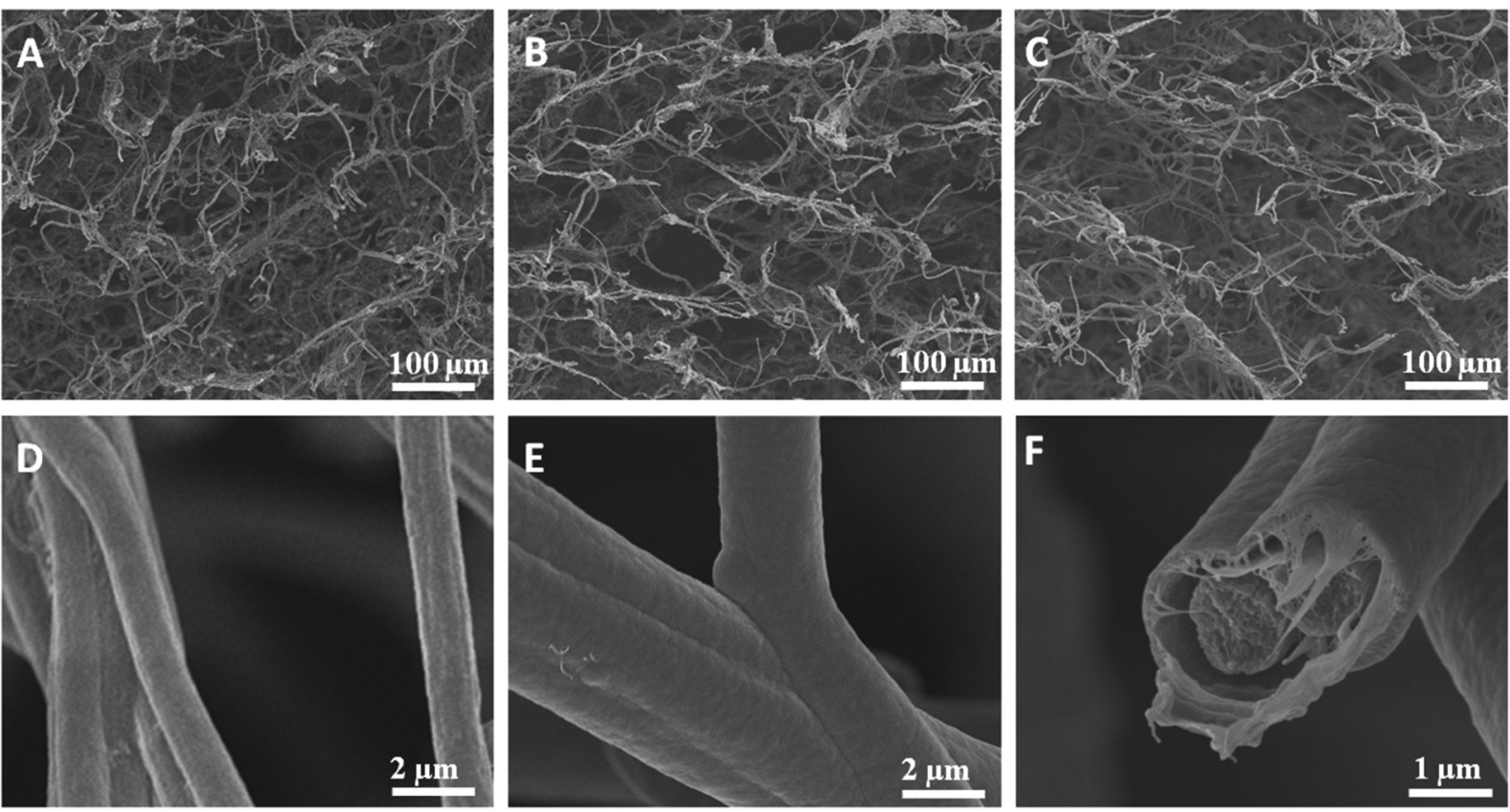

Fig. 2 SEM images of original sponge $1\left(A, 8.42 \mathrm{mg} \mathrm{cm}^{-3}\right)$, sponge $2\left(B, 7.43 \mathrm{mg} \mathrm{cm}^{-3}\right)$, sponge $4\left(C, 5.16 \mathrm{mg} \mathrm{cm}^{-3}\right)$, higher magnification of sponge 4 (D), sponge 4 coated with $1000 \mathrm{~nm}$ PPX (E, sponge 4-1000), and the corresponding cross section of sponge 4-1000.

Table 2 Densities of sponges before and after PPX coating

\begin{tabular}{lcccc}
\hline \multirow{5}{*}{ PPX thickness (nm) } & \multicolumn{4}{l}{ Density $\left(\mathrm{mg} \mathrm{cm}^{-3}\right)$} \\
\cline { 2 - 5 } & Sponge 1 & Sponge 2 & Sponge 4 & Sponge 5 \\
\hline 0 & 8.42 & 7.43 & 5.16 & 4.34 \\
100 & 9.41 & 8.55 & 6.40 & 4.83 \\
280 & 12.45 & 10.99 & 7.30 & 6.41 \\
360 & 14.48 & 13.05 & 8.66 & 7.42 \\
1000 & 22.59 & 20.06 & 13.93 & 12.15 \\
& & & & \\
\hline
\end{tabular}

freeze-drying. The original electrospun fibre sponges exhibited densities in the range of $4.34-8.42 \mathrm{mg} \mathrm{cm}^{-3}$. Upon coating with different thicknesses of PPX, the composite sponges showed a considerable density variation from 4.83 to $22.59 \mathrm{mg}$ $\mathrm{cm}^{-3}$ without a major change in the pore structure of the sponges. This diversity in density would greatly promote the sponges in different applications.

The compression properties of sponges with different densities and PPX coating thicknesses were investigated. The compression stress-strain curves are shown in Fig. 3 and the corresponding data are summarized in Table 3. As expected, a higher sponge density led to higher compression strength. When compressed at $50 \%$ strain, sponge 5 (density = $4.34 \mathrm{mg} \mathrm{cm}^{-3}$ ), sponge 4 (density $=5.16 \mathrm{mg} \mathrm{cm}^{-3}$ ), sponge 2 $\left(\right.$ density $\left.=7.43 \mathrm{mg} \mathrm{cm}{ }^{-3}\right)$, and sponge 1 (density $=8.43$ $\mathrm{mg} \mathrm{cm} \mathrm{cm}^{-3}$ ) possessed a compression strength of $0.26,0.47$, 0.76 , and $0.92 \mathrm{kPa}$, respectively. After coating with PPX, the composite sponges showed significant enhancement in compression stress. The composite sponges with a coating of $100 \mathrm{~nm}$ thick PPX exhibited compression strength more than two times compared to that of the bare sponges. When $1000 \mathrm{~nm}$ of PPX were coated on the sponges, the compression strength increased more than 10 times the original sponges. One cyclic compression test was also performed to assess the mechanical performance of the sponges before and after PPX coating. As shown in Fig. 3, it is obvious that the second compression curves (c) are always under the first compression curves (a) and there are blank areas in between curves a and c. These areas could be used to access the energy loss during the cyclic compression test. The sponges with higher density showed higher compression strength, but they also showed much more energy loss during the cyclic test. Although there was energy loss, the ultimate compression strength of the second compression could return to the same values as the first test showed. Fig. 4 shows the relationship between the compression strength and the densities of the sponges. It was obvious that the thicker PPX coating led to a higher density and the sponges with higher densities possessed higher compression strength. Furthermore, a coated sponge (density was $5.0 \pm 0.1 \mathrm{mg} \mathrm{cm}{ }^{-3}$, before coating) with $100 \mathrm{~nm}$ PPX can support a piece of dry ice on the top without compression deformation, whereas an uncoated sponge is not able to bear such a force. These sponges have low thermal conductivity of about $0.05 \mathrm{~W}(\mathrm{~K} \mathrm{~m})^{-1}$. A sponge could protect human skin from dry ice $\left(\mathrm{CO}_{2},-78^{\circ} \mathrm{C}\right)$ as shown in a real time video in the ESI. $\dagger$

Previous research by Boduroglu et al. reported that the structured PPX films showed superhydrophobicity with a water contact angle (WCA) of about $1522^{\circ} .{ }^{16}$ A PPX coating on sponge fibres could also lead to a significant increase of the hydrophobicity of the sponges, which was indeed the case but not as 

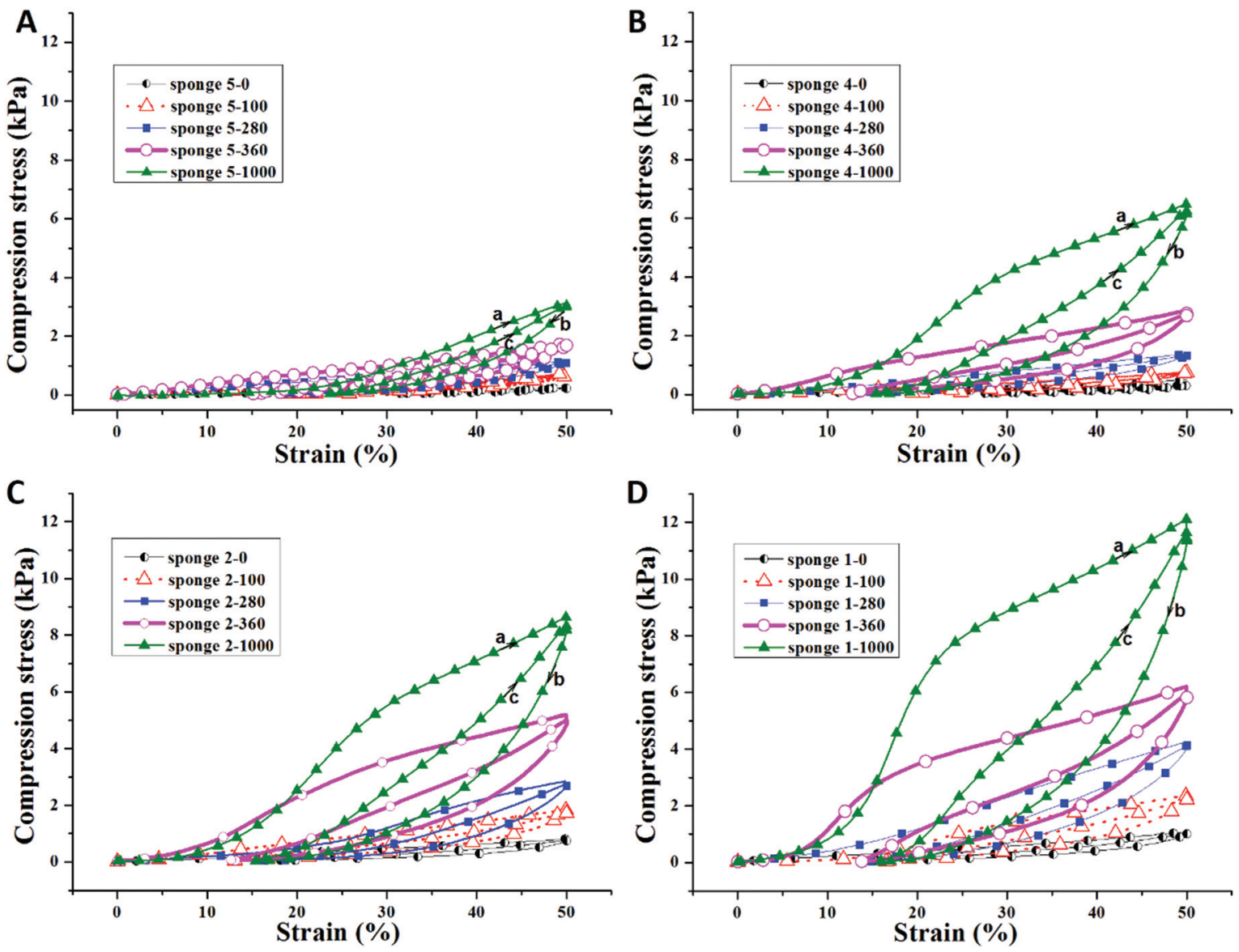

Fig. 3 Cyclic compression test of sponges with 0, 100, 280, 360, and $1000 \mathrm{~nm}$ thick PPX coating. The upper curve (a): first compression cycle; the middle curve (b): release; the bottom curve (c): the second compression cycle.

Table 3 Compression stress of sponges before and after PPX coating

\begin{tabular}{lllll}
\hline \multirow{2}{*}{ PPX thickness (nm) } & \multicolumn{4}{l}{ Compression stress (kPa) } \\
\cline { 2 - 5 } & Sponge 1 & Sponge 2 & Sponge 4 & Sponge 5 \\
\hline 0 & 0.92 & 0.76 & 0.47 & 0.26 \\
100 & 2.31 & 1.93 & 0.97 & 0.81 \\
280 & 4.13 & 2.74 & 1.40 & 1.20 \\
360 & 6.21 & 5.19 & 2.89 & 1.72 \\
1000 & 12.13 & 8.67 & 6.52 & 3.08
\end{tabular}

expected. Fig. 5A presents the typical WCA of sponge 2 with varying PPX coating thickness. The as-prepared sponge 2 had a WCA of $119^{\circ}$. When the PPX thickness increased to $280 \mathrm{~nm}$, the composite sponge (sponge 2-280) became superhydrophobic with a WCA of $156^{\circ}$. A further increase of the PPX coating thickness led to a decrease of WCA, but the WCA (144 and $131^{\circ}$ ) was still much higher than that of the as-prepared sponge $\left(119^{\circ}\right)$. Fig. 5B reveals the relationship between the WCA and the PPX thickness. Generally, the WCA on PPX coated sponges showed a trend of an increase in contact angle with thickness up to a certain value and then decreased on a

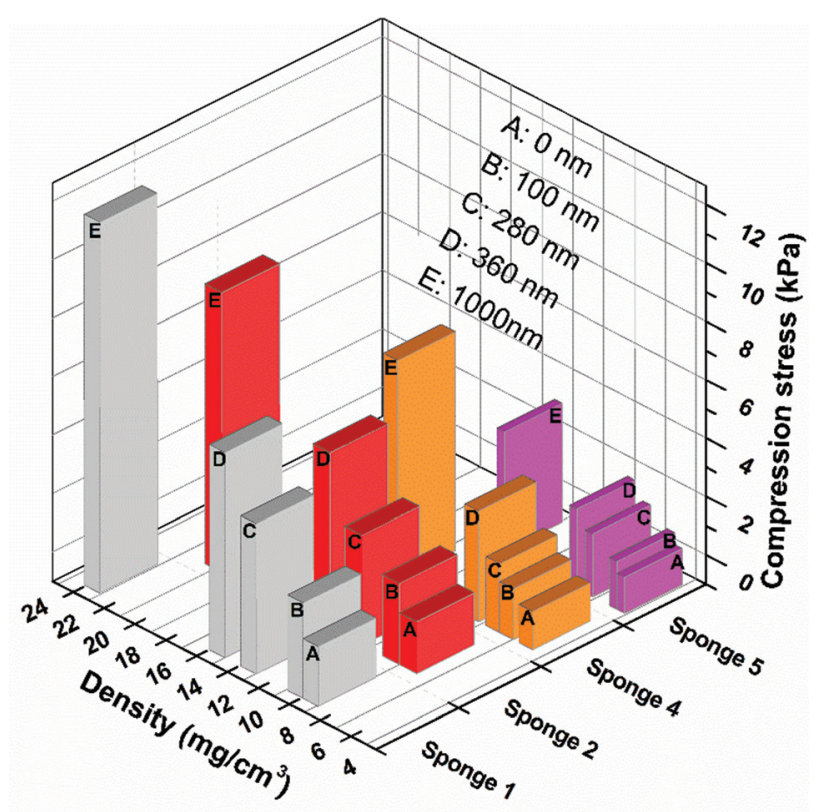

Fig. 4 Compression stress of sponges before and after PPX coating as a function of density. 

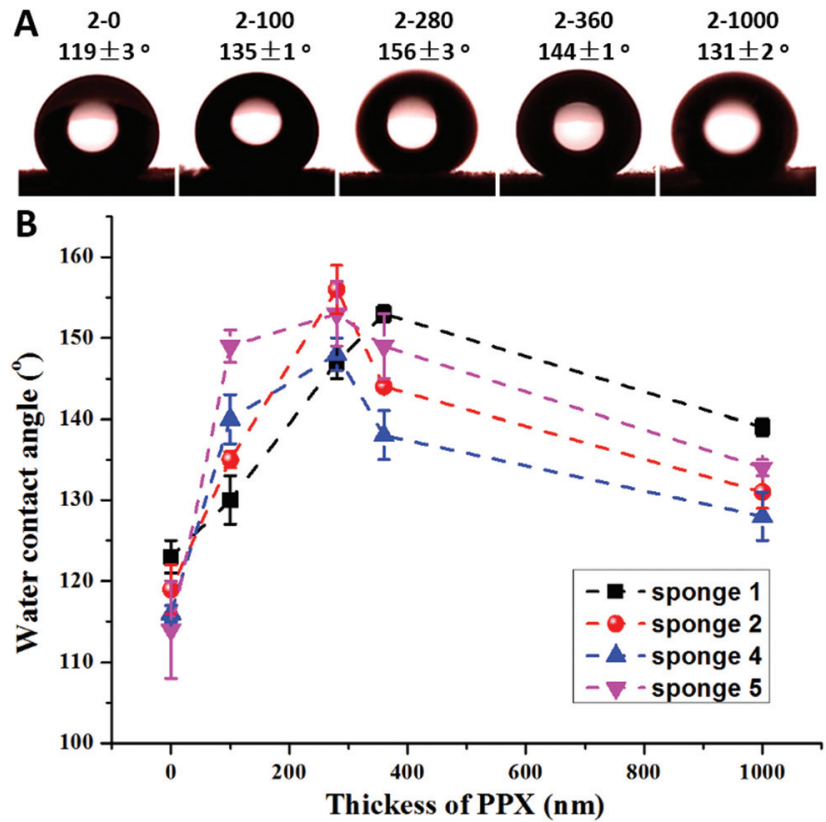

Fig. 5 Typical water contact angle of sponge 2 with different PPX coating thicknesses (A) and water contact angles as a function of the PPX coating thickness of sponges 1, 2, 4, and 5 (B).

further increase in PPX coating thickness. The optimum PPX thickness providing the highest contact angles was about $280 \mathrm{~nm}$. An analogous trend of the hydrophobicity as a function of PPX thickness was found for electrospun mats (see the ESI Fig. S1†).

Surface structures play an important role on the WCA. In this study, the surfaces of the sponge fibres were observed by SEM. The as-prepared sponge fibre showed many nanopores (Fig. 6A), which could be attributed to the phase separation during the preparation of the sponge. These pores led to a
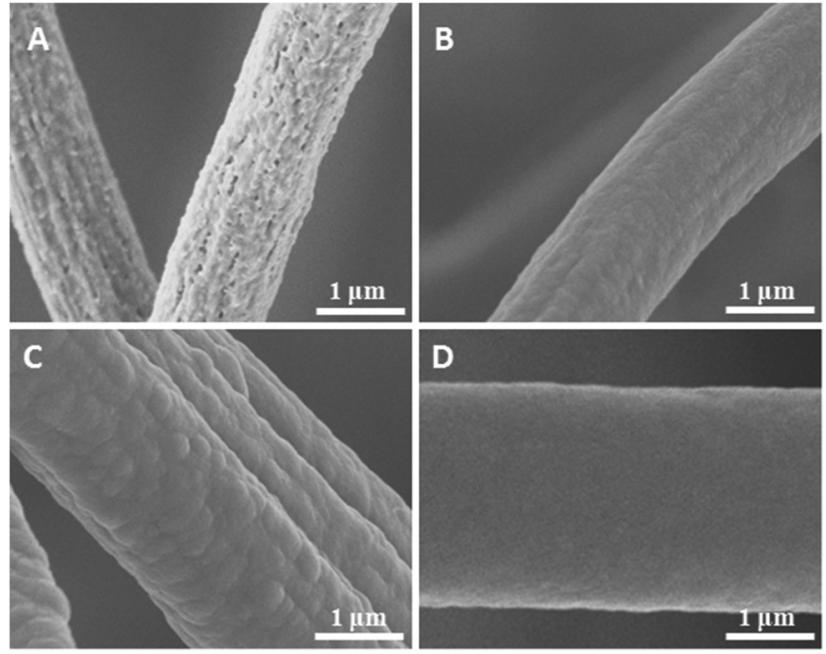

Fig. 6 SEM images of sponge (sponge 2) fibres with the PPX thicknesses of 0 (A), 100 (B), 280 (C), and $1000 \mathrm{~nm}(\mathrm{D})$. rough surface and this may be the reason for the hydrophobicity of the as-prepared electrospun polymer sponge. The coating of PPX greatly changed the surface morphology of the composite sponge fibres. When coated with $100 \mathrm{~nm}$ PPX, the fibre surface became smooth but some salient features were observed (Fig. 2B), which could be due to the occupation of the nanopores of the as-prepared fibres. The composite sponge fibres exhibited bigger salient features and much smoother surface when the sponges were coated with 280 and $1000 \mathrm{~nm}$ PPX, respectively (Fig. 6C and D). This explains the lower WCA at higher PPX coating thicknesses. Quite obviously, the hydrophobicity of fibrous materials as a function of PPX coating thickness is a combined effect of inherent hydrophobicity and surface roughness which becomes smaller when thicker PPX layers flatten fibrous substrates.

PPX has excellent solvent resistance. Therefore, we expected improved solvent resistance of the sponges by PPX coating, which would open up many new chances for advanced applications. The solvent resistance of the sponges with and without PPX coating was investigated in water, ethanol, acetone, and chloroform. As shown in Fig. 7, the sponges with the size of $3 \mathrm{~mm} \times 5 \mathrm{~mm} \times 7 \mathrm{~mm}$ were put in a $1.5 \mathrm{~mL}$ vial with $0.8 \mathrm{~mL}$ solvents. Both uncoated and coated sponge floated on the surface of water but they were totally soaked by organic solvents (Fig. 7A and B). Interestingly, the sponges sank to the bottom of the vial in ethanol and acetone, but floated in chloroform due to the density difference between the sponge polymer and solvents: the polymer density of the sponges was larger than those of ethanol and acetone, but smaller than the density of chloroform. It is necessary to point out that the stability of non-coated sponges in organic solvents depends upon the type of the solvent used. The sponges kept their original shapes in ethanol even for a very long time but swelled a little in acetone and chloroform. Coated sponges had higher shape stability even after intense shaking (Fig. 7D).
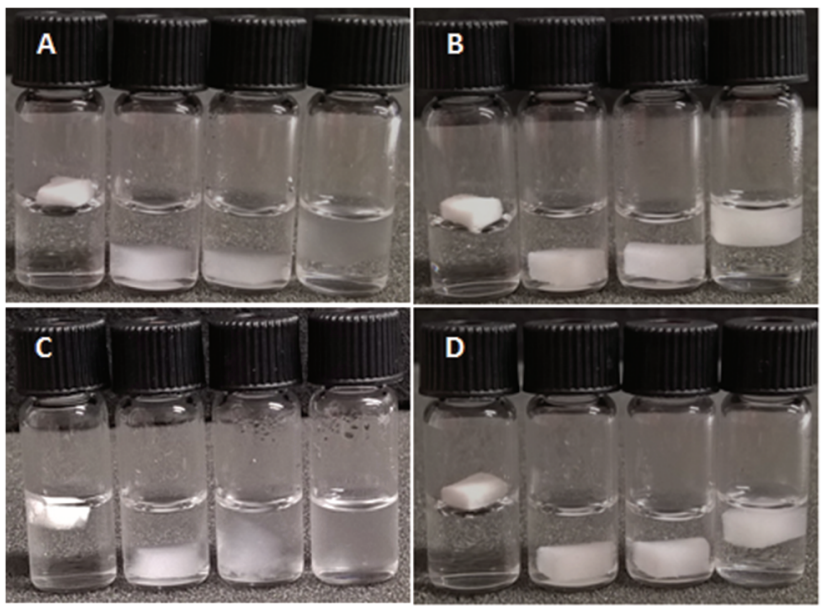

Fig. 7 Sponges in different solvents (from left to right: water, ethanol, acetone, chloroform). (A) before coating, (B) PPX coating thickness of $280 \mathrm{~nm},(C)$ and (D) after intense shaking of (A) and (B) respectively. 
However, uncoated sponges lost their structure in acetone and chloroform during shaking by hand (Fig. 7C), which forces the formation of short fibres and these short fibres can be reused for the preparation of new sponges in dioxane.

\section{Conclusions}

Ultralight composite sponges were achieved by CVD coating with different coating thicknesses of PPX on the as-prepared short electrospun polymer sponges under ambient conditions. The density, compression strength, and the water contact angle of the composite sponges could be well tuned by adjusting the thickness of the PPX coating layer. However, with higher PPX layer thickness the hydrophobicity of the sponges decreased, which could be explained by planarization of the fractal structure on the fibre surfaces. In addition, the PPX coating could significantly improve the solvent resistance of the sponges and retain their shape in various solvents. The PPX coating removes the inherent disadvantage of lower chemical and mechanical stability of polymeric sponges made from short electrospun fibres without destroying their porous structure. This is a big step forward in the direction of future use of 3D porous fibrous scaffolds under harsh conditions. With this the PPX coated sponges have become of particular interest for separation applications. Due to the low thermal conductivity and the improvement of the mechanical properties of sponges after PPX coating, these coated sponges can be applied in the heat insulation field as a new kind of light weight material.

\section{Acknowledgements}

The authors are indebted to DFG for financial support (SFB840) and to Specialty Coating Systems for the donation of paracyclophane. We are thankful to Mrs Bianca Uch for taking the video with dry ice on sponge.

\section{Notes and references}

1 Y. K. Akimov, Instrum. Exp. Tech., 2003, 46, 287-299.
2 V. Chabot, D. Higgins, A. Yu, X. Xiao, Z. Chen and J. Zhang, Energy Environ. Sci., 2014, 7, 1564-1596.

3 S. Nardecchia, D. Carriazo, M. L. Ferrer, M. C. Gutierrez and F. del Monte, Chem. Soc. Rev., 2013, 42, 794-830.

4 P. C. Thapliyal and K. Singh, J. Mater., 2014, 2014, 10.

5 S. Zhong, Y. Zhang and C. T. Lim, Tissue Eng., Part B, 2011, 18, 77-87.

6 S.-H. Shin, O. Purevdorj, O. Castano, J. A. Planell and H.-W. Kim, J. Tissue Eng., 2012, 3.

7 J. M. Holzwarth and P. X. Ma, J. Mater. Chem., 2011, 21, 10243-10251.

8 S. Chen, H. Hou, F. Harnisch, S. A. Patil, A. A. CarmonaMartinez, S. Agarwal, Y. Zhang, S. Sinha-Ray, A. L. Yarin and A. Greiner, Energy Environ. Sci., 2011, 4, 1417-1421.

9 J. Wu, N. Wang, L. Wang, H. Dong, Y. Zhao and L. Jiang, ACS Appl. Mater. Interfaces, 2012, 4, 3207-3212.

10 Y. Si, J. Yu, X. Tang, J. Ge and B. Ding, Nat. Commun., 2014, DOI: 10.1038/ncomms6802; Y. Si, Q. Fu, X. Wang, J. Zhu, J. Yu, G. Sun and B. Ding, ACS Nano, 2015, 9, 3791-3799.

11 G. Duan, S. Jiang, V. Jérôme, J. H. Wendorff, A. Fathi, J. Uhm, V. Altstädt, M. Herling, J. Breu, R. Freitag, S. Agarwal and A. Greiner, Adv. Funct. Mater., 2015, 25, 2850-2856.

12 T. Xu, J. M. Miszuk, Y. Zhao, H. Sun and H. Fong, Adv. Healthcare Mater., 2015, 4, 2238-2246.

13 H. Hou, Z. Jun, A. Reuning, A. Schaper, J. H. Wendorff and A. Greiner, Macromolecules, 2002, 35, 2429-2431.

14 P. Simon, S. Mang, A. Hasenhindl, W. Gronski and A. Greiner, Macromolecules, 1998, 31, 8775-8780.

15 A. Greiner, S. Mang, O. Schäfer and P. Simon, Acta Polym., 1997, 48, 1-15.

16 S. Boduroglu, M. Cetinkaya, W. Dressick, A. Singh and M. Demirel, Langmuir, 2007, 23, 11391-11395.

17 H. Shao, X. Hu, K. Xu, C. Tang, Y. Zhou, M. Shuai, J. Mei, Y. Zhu and W.-m. Lau, RSC Adv., 2015, 5, 55713-55719.

18 K. Y. Suh, R. Langer and J. Lahann, Appl. Phys. Lett., 2003, 83, 4250-4252.

19 C. Hassler, R. P. von Metzen, P. Ruther and T. Stieglitz, J. Biomed. Mater. Res., Part B, 2010, 93, 266-274.

20 K. Yamashita, T. Mori and T. Mizutani, J. Phys. D: Appl. Phys., 2001, 34, 740.

21 I. Yilgor, S. Bilgin, M. Isik and E. Yilgor, Polymer, 2012, 53, 1180-1188. 